\title{
Strain differences in runway learning in the rat
}

\author{
GORDON M. HARRINGTON \\ University of Northern Iowa, Cedar Falls, Iowa 50613
}

\begin{abstract}
Running speed during runway conditioning was measured for 567 rats from 12 inbred strains: ACI, A990, A35322, F344, INR, IR, MNR/Har, MNRA, MR/Har, TS1, TS3, WAG. The results provide parametric data for methodological use and add to the standardization of these strains as behaviorally defined lines.
\end{abstract}

Hull (1934) originated use of the runway or alley as an instrument for the study of conditioning processes. It became the principal apparatus for much of the research in the Hull-Spence framework. Of course, the Skinner box has since replaced it as the primary device for the study of animal learning. However, this shift reflects a change in emphasis and objectives rather than an improved alternative method. The Skinner box provides a means of studying the structure of response sequences, while the runway provides a means for examining the topography of individual responses. For the latter purpose, the runway remains useful.

Since the runway played such an important methodological role, it is rather remarkable that there appears to be no literature relating genetic variation to runway learning. In fact, the runway seems to have been used as an instrument in genetic studies only as a social competition device (Masur \& Benedito, 1974). One might reasonably have expected that the active and extensive investigation of heredity and maze learning originating with Tolman (1924) would have been extended to the runway-the ultimate simplification of the maze. The present study examined genetic variation in runway performance as reflected in strain differences. In other disciplines, recent years have seen a major concern with precise specification and standardization of lines of laboratory animals (International Committee on Laboratory Animals, 1971). This study is one of a number of studies (Harrington, 1971a, 1971b, 1979a, 1979b, 1979c, 1979d, 1979e, 1979f, 1979g, 1979h; Harrington \& Hellwig, 1979a, $1979 \mathrm{~b}$ ) intended to provide behavioral standardization data for those 12 genetically defined lines of rats having the highest citation frequency in the behavioral literature.

\section{METHOD}

\section{Subjects}

Subjects were 567 rats, $114-128$ days of age, with a minimum of 20 animals of each sex within each of the following 12 inbred strains: ACI/Har, A990/Har, A35322/Har, F344/DuHar, INR, IR, MNR/Har, MNRA (formerly MNR-a/Har), MR/Har, TS1, TS3, WAG/Har. All lines are designated by the standard nomenclature for this species and are described in the fourth international listing (Festing \& Staats, 1973). Animals were bred and maintained at $25.5^{\circ} \mathrm{C} \pm 1.1^{\circ} \mathrm{C}$ and $40 \% \pm 5 \%$ relative humidity. Breeders and pups were housed under natural light cycle. Pups were handled for $1 \mathrm{~min}$ on alternate days from age 14 to 45 days. At 45 days they were transferred to individual cages with 24-h light cycle. More detailed descriptions are available else where (Harrington, 1968).

\section{Apparatus}

The apparatus was a black closed runway 152.4 by 9 by $9 \mathrm{~cm}$ with a $5.4-\mathrm{cm}$ opening in the top covered with $1.25-\mathrm{cm}$ wire mesh. Sides and top were rapidly removable for conversion to an open runway. The runway was suspended in a white ganzfeld. Start- and goalboxes were $34.9 \mathrm{~cm}$ long with start and end gates $11.5 \mathrm{~cm}$ from the runway. The cross-section was the same as that of the closed runway except that top was solid between gate and runway. Proceeding from start to end, photocells were mounted $6.35 \mathrm{~cm}$ past the start gate and $4 \mathrm{~cm}$ past the end gate.

\section{Procedure}

Starting 2 weeks prior to testing, subjects were placed on restricted food intake and progressively reduced to $85 \%$ of projected ad-lib body weight. One day of pretraining preceded testing. Each animal was fed 1045 -mg Noyes pellets. After the pellets were consumed, each animal was transported to the testapparatus site in its home cage. Five pellets were placed at the end of the goalbox. The animal was placed in the goalbox with head toward the gate. After the pellets had been consumed, the animal was returned to its cage. This goalbox feeding sequence was repeated twice more, first with three then with two pellets. Animals were tested for 10 days for 10 massed trials/day with alternate trials on the closed and the open runways. Reinforcement was 1 pellet/trial. Time between photocells was automatically recorded. Animals were arbitrarily assigned a running time of $5 \mathrm{~min}$ if they failed to enter the goalbox within that time period.

\section{RESULTS AND DISCUSSION}

The mean and standard deviations of running time per trial are shown for each strain and sex combination in Table 1. The fastest strains were MNRA, INR, TS3, and WAG. However, the INR line showed less in trastrain variance than did the others. This would seem to render it particularly useful for runway studies. In that context it is of some historical interest to note that this strain was created by inbreeding from the stocks used by Spence. The F344 line was distinguished by its poor runway performance. 
Table 1

Running Time of 12 Inbred Strains of Rats in an Alternating Closed and Open Runway

\begin{tabular}{lrrrrr} 
& \multicolumn{3}{c}{ Mean Time per Trial* } \\
\cline { 2 - 3 } \multicolumn{1}{c}{ Strain } & \multicolumn{2}{c}{ Males } & & Females \\
\cline { 2 - 3 } \cline { 5 - 6 } Mean & SD & & Mean & SD \\
\hline ACI/Har & 145 & 79 & 86 & 71 \\
A990/Har & 144 & 82 & 164 & 103 \\
A35322/Har & 98 & 64 & 92 & 86 \\
F344/DuHar & 209 & 84 & 164 & 76 \\
INR & 60 & 37 & 27 & 9 \\
IR & 143 & 78 & 103 & 53 \\
MNR/Har & 77 & 80 & 45 & 72 \\
MNRA & 48 & 63 & 31 & 52 \\
MR/Har & 90 & 74 & 37 & 29 \\
TS1 & 138 & 82 & 52 & 31 \\
TS3 & 59 & 44 & 34 & 28 \\
WAG/Har & 62 & 57 & 33 & 27 \\
\hline
\end{tabular}

Note $-N \geqslant 20$ for each sex within each strain.

*10 trials/day for 10 days.

\section{REFERENCES}

Festing, M., \& StaAts, J. Standardized nomenclature for inbred strains of rats. Transplantation, 1973, 16, 221-245.

HARRINGTON, G. M. Genetic-environmental interaction in "intelligence." I: Biometric genetic analysis of maze performance of Rattus Norvegicus. Developmental Psychobiology, 1968, 1, 211-218.

HARRINGton, G. M. Strain differences among rats initiating exploration of differing environments. Psychonomic Science, 1971, 23, 348-349. (a)

HARRINGTON, G. M. Strain differences in rotating wheel activity of the rat. Psychonomic Science, 1971, 23, 363-364. (b)

HARRINGTON, G. M. Strain differences in open field behavior of the rat. Psychonomic Science, 1972, 27, 51-53.
HARRINgton, G. M. Strain differences in activity of the rat in a shuttle stabilimeter. Bulletin of the Psychonomic Society, 1979, 13, 149-150. (a)

HARRINGton, G. M. Strain differences in activity of the rat using a home cage stabilimeter. Bulletin of the Psychonomic Society, 1979, 13, 151.152. (b)

HARRINGton, G. M. Strain differences in free operant leverpress levels in the rat. Bulletin of the Psychonomic Society, 1979, 13, 153-154. (c)

HARRINGTON, G. M. Strain differences in light-contingent barpress behavior of the rat. Bulletin of the Psychonomic Society, 1979, 13, 155-156. (d)

Harrington, G. M. Strain differences in open-field behavior of the rat. II. Bulletin of the Psychonomic Society, 1979, 13, 85-86. (e)

HARRINGTON, G. M. Strain differences in passive avoidance conditioning in the rat. Bulletin of the Psychonomic Society, 1979, 13, 157-158. (f)

HaRrington, G. M. Strain differences in shuttle avoidance conditioning in the rat. Bulletin of the Psychonomic Society, 1979, 13, 161-162. (g)

HARRINGTON, G. M. Strain differences in simple operant barpress acquisition to an auditory stimulus by rats. Bulletin of the Psychonomic Society, 1979, 13, 163-164. (h)

Harrington, G. M., \& Hellwig, L. R. Strain differences in basal metabolism of behaviorally defined rats. Bulletin of the Psychonomic Society, 1979, 13, 165-166. (a)

Harrington, G. M., \& Hellwig, L. R. Strain differences in organ weights of behaviorally defined rats. Bulletin of the Psychonomic Society, 1979, 13, 167-169. (b)

HulL, C. L. The concept of habit-family hierarchy, and maze learning. Part I. Psychological Bulletin, 1934, 41, 33-54.

International Committee on Laboratory Animals. Defining the laboratory animal. Washington, D.C: National Academy of Sciences, 1971.

Masur, J., \& Benedito, M. A. C. Genetic selection of winner and loser rats in a competitive situation. Nature, 1974, 249, 284.

Tolman, E. C. Inheritance of maze learning ability in rats. Journal of Comparative Psychology, 1924, 4, 1-18.

(Received for publication January 16, 1979.) 